\title{
Effect of tool pin profile on mechanical properties of Al6082 and Al6082-Cu composite by friction stir processing
}

\author{
Vikrant Yadav1, Vinay Kumar ${ }^{2}$, Vatsalya Tiwari ${ }^{3}$ \\ 1,2,3 (Delhi Technological University, India)
}

\begin{abstract}
With the surge of applications incorporating MMCs which provide enhanced mechanical properties, the need of better technologies for fabrication of these materials has attracted lot of work. One of the latest techniques to produce these specialised defect-free materials is Friction Stir Processing (FSP) which is derived from the principles of Friction Stir Welding. In the present study, a metal matrix composite was fabricated by using Al-6082 T651 alloy as the substrate. Copper particles with $37 \mu \mathrm{m}$ particle size were the added reinforcement. Two tool pin profiles; a square profile and a threaded cylindrical profile, were employed to carry out the processing. With each tool pin profile, two specimens; one with reinforcement and one without reinforcement, were processed. The five specimens including the base metal were then critically examined for changes in mechanical properties. Rockwell test for hardness was conducted and tensile properties evaluated using digital UTM.
\end{abstract}

Keywords - MMC, Aluminium 6082, Tool Pin Profile, Tensile Properties, Hardness, Elongation.

\section{Introduction}

The modern high service applications in aerospace, automotive and other manufacturing sectors call for high duty materials that can provide long life under extreme conditions of service. Employment of metal-matrix composites (MMCs) serves the purpose. The reinforcing material can be another metal ( $\mathrm{Cu}, \mathrm{Mn}$, etc.) or ceramic phases ( $\mathrm{SiC}, \mathrm{WC}, \mathrm{TiC}$, etc.). These materials exhibit high strength, high elastic modulus and improved resistance to wear, creep and fatigue. However these also suffer from loss in ductility and toughness due to incorporation of reinforcement in the main core [1]. It is hence desirable that only the surface layer is fabricated by the foreign material so that the main bulk retains the toughness and surface layer develops the requisite hardness and hence wear resistance. MMCs are obviously costlier than the parent material and hence lot of work has gone in past few decades to develop and optimise new technologies to have low cost but effective composite materials.

Aluminium alloy 6082 is a medium strength alloy and has the highest strength of the 6000 series alloys. It is known as a structural alloy and used in applications involving high stresses, in trusses, bridges, cranes, milk churns and transport applications. As a relatively new alloy, the higher strength of 6082 has led to replacement of alloy 6061 in many applications. It also characterizes excellent corrosion resistance, good weldability and machinability. Recent works have revealed that addition of $\mathrm{Mn}, \mathrm{Mg}$ and/or $\mathrm{Cu}$ phases in aluminium matrix have significantly improved the mechanical properties of the materials. Out of various surface fabrication techniques, a latest and cost effective technique namely Friction Stir Processing (FSP) has witnessed a lot of work since its inception in the past decade. FSP was developed by Mishra et al. [2,3] based on basic principles of friction stir welding (FSW). FSW was developed at The Welding Institute (TWI) of UK in 1991 as a solid state joining process [4]. A non consumable rotating tool consisting of a pin and shoulder is inserted into given material and traversed along a desired line for microstructural modification in that region [1]. The intense frictional heating and plastic deformation leads to formation of defect free, recrystallised and fine grained equiaxed microstructure. FSP performed on 5083Al using nano-sized $\mathrm{Cu}$ particles showed higher tensile strength, ultimate tensile strength, elongation and hardness than the base metal [5]. On a work with hybrid MMC using Al5083 plate with SiC and $\mathrm{MoS}_{2}$ particles, the hardness and wear resistance properties were improved by FSP [6]. Even dispersion of fullerene into A5083 matrix using FSP resulted in increased microhardness by promotion of grain refinement due to pinning effect and high hardness of fullerene particles [7].

In the present investigation, Aluminium 6082 and Copper reinforcement have been used as very little work has gone into study of this particular alloy with any reinforcement. FSP is employed to generate MMCs using Aluminium 6082-T651 plate with copper particle reinforcement with two different tool pin profiles and to study the effect on mechanical properties due to both inclusion of $\mathrm{Cu}$ in the matrix and the variation of tool profile. Square and threaded cylindrical pin profiles were employed and copper powder with 400 mesh size added in the aluminium substrate. 


\section{Experimental Procedure}

Commercial 6082-T651 Aluminium plates $-6 \mathrm{~mm}$ thick, $70 \mathrm{~mm}$ wide and $230 \mathrm{~mm}, 4$ plates in total were cut out from a parent sheet using an automatic wire cut machine. The composition of Aluminium 6082-T651 by weight is $\mathrm{Mn} 1 \%, \mathrm{Mg} 1.2 \%$, Si $1.3 \%, \mathrm{Fe} 0.5 \%$ and $\mathrm{Zn} \mathrm{Ti} \mathrm{Cr}$ in small amounts and balance Aluminium. The tools were made of AISI H-13 Tool Steel with two pin profiles ; square and threaded cylindrical profiles, both concentric with flat circular shoulders. One tool was made with no pin i.e. a flat tool for the purpose of covering up the composite copper metal powder. The dimensions of the tool are shown in Table 1.

Table 1: Tool Dimensions

\begin{tabular}{|l|l|}
\hline Dimension & Values \\
\hline Shoulder Diameter & $16 \mathrm{~mm}$ \\
\hline Pin Depth & $2.5 \mathrm{~mm}$ \\
\hline Diameter of pin of circular cross section & $5.5 \mathrm{~mm}$ \\
\hline Side of pin of square cross section & $3.89 \mathrm{~mm}$ \\
\hline Pitch of threads & 1.5 Threads per $\mathrm{mm}$ \\
\hline
\end{tabular}

The copper metal powder used was of 300 mesh size. Friction stir process was carried out on a vertical milling machine. Four cases were considered; 1) FSP with cylindrical tool pin, 2) FSP with square profile tool pin, 3) FSP with cylindrical tool pin with copper metal powder reinforcement and 4) FSP with square profile tool pin with copper metal powder reinforcement.

The tool rotation rate used was $1000 \mathrm{rpm}$ and the transverse speed of the tool was $16 \mathrm{~mm}$ per second in all the cases. Single pass processing was simply done on the plates using the simple cylindrical and the square profile tool.

For FSP using the copper powder, a groove of depth $2 \mathrm{~mm}$ and width $2 \mathrm{~mm}$ was cut along the length of two of the plates. Copper metal powder was filled in the groove and the groove containing the powder was covered by processing the plate once by the flat shoulder tool. Two such plates were prepared and further processing was done using the threaded cylindrical tool and a square profile tool. After all the plates were processed, test specimen for tensile strength, microstructure and hardness were cut from the FSPed region of the processed plates. The specimen cut for hardness test was of circular profile of diameter $10 \mathrm{~mm}$. The specimens went under Rockwell Hardness Testing Machine, with class B, Shell Ball type indenter (Dia=1/16th Inches) with major load-100kgf and minor load 10Kgf. For tensile Strength, four dogbone specimens were prepared from the processed plates and one from the base plate as per ASTM standards. Tests were conducted on the specimens using Digital UTM.
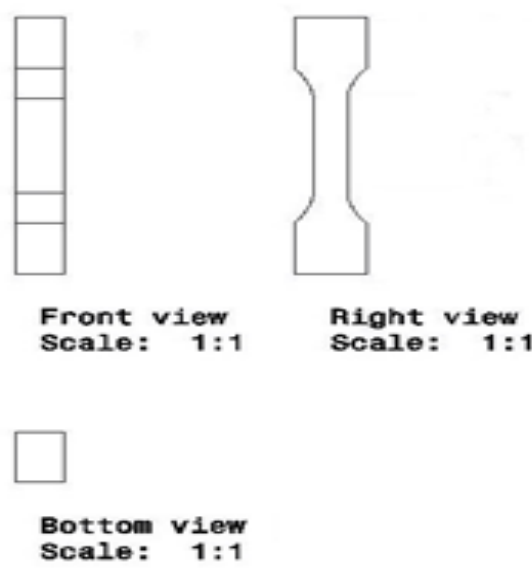

Fig.1: Tension Test Specimen

\section{Results And Discussions}

3.1 Tensile Strength and Hardness

Table 2: UTS values

\begin{tabular}{|l|c|}
\hline Specimen & Ultimate Tensile Strength (MPa) \\
\hline Base metal without composites & 316 \\
\hline Threaded Cylindrical profile without composite & 152 \\
\hline Square Profile without composites & 133 \\
\hline Threaded Cylindrical Profile with composites & 161 \\
\hline Square Profile with Composite & 156 \\
\hline
\end{tabular}


Table 3: Hardness Rockwell B (HRB) values

\begin{tabular}{|l|c|}
\hline Specimen & Hardness B Rockwell \\
\hline Base metal without composites & 33 \\
\hline Threaded Cylindrical profile without composite & 70 \\
\hline Square Profile without composites & 64 \\
\hline Threaded Cylindrical Profile with composites & 84 \\
\hline Square Profile with Composite & 77 \\
\hline
\end{tabular}

The base metal exhibited highest ultimate tensile strength (UTS) of 316MPa but lowest hardness of 33B Rockwell. The specimen processed without copper reinforcement had UTS of 152MPa and Hardness of 74B Rockwell for processing done with threaded cylindrical profile tool whereas a UTS of $133 \mathrm{MPa}$ and Hardness of 64B Rockwell for processing done with square profile tool. For sample processed with copper powder using the threaded cylindrical tool pin profile, UTS of $161 \mathrm{MPa}$ and hardness of 84B Rockwell was obtained whereas for the processing using square profile tool with reinforcement, UTS of 156MPa and Hardness of 77B Rockwell was measured.

The samples processed without the $\mathrm{Cu}$ powder were defect free and the stir zone was characterised by equiaxed and finer grains due to severe plastic deformation and frictional heating leading to recrystallisation $[5,8,9]$. On the contrary, the specimens processed with the copper composite possessed groove defects and great particle agglomeration leading to non homogeneous properties inferior to that of the base metal. The probable reason for the defects is wider gap of powder filled slot as well as too high a rotational speed and traverse speed.

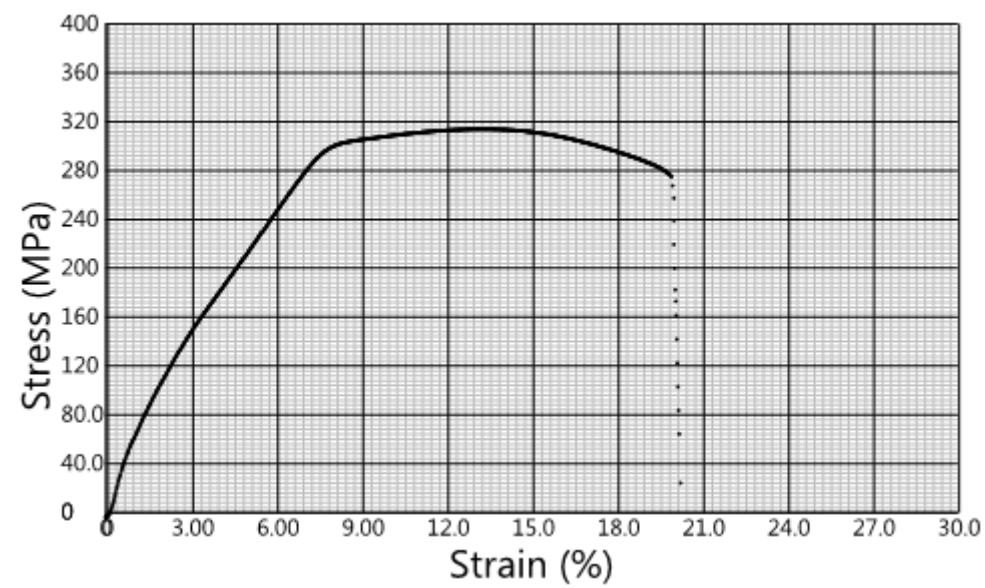

Fig.1: Stress-Strain Curve For Pure Al-6082 profile

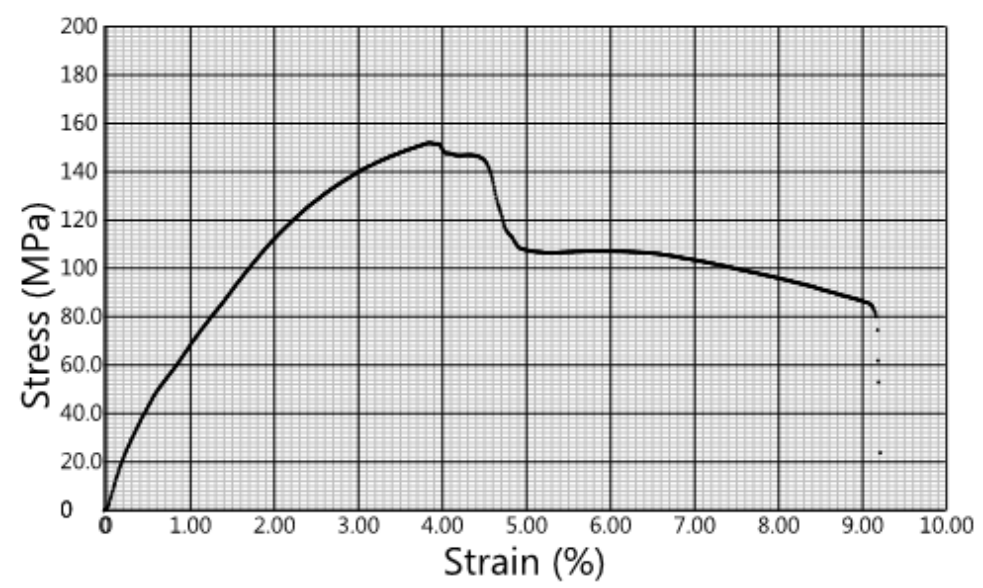

Fig.2: Stress-Strain Curve for Plate processed with threaded cylindrical pin profile 


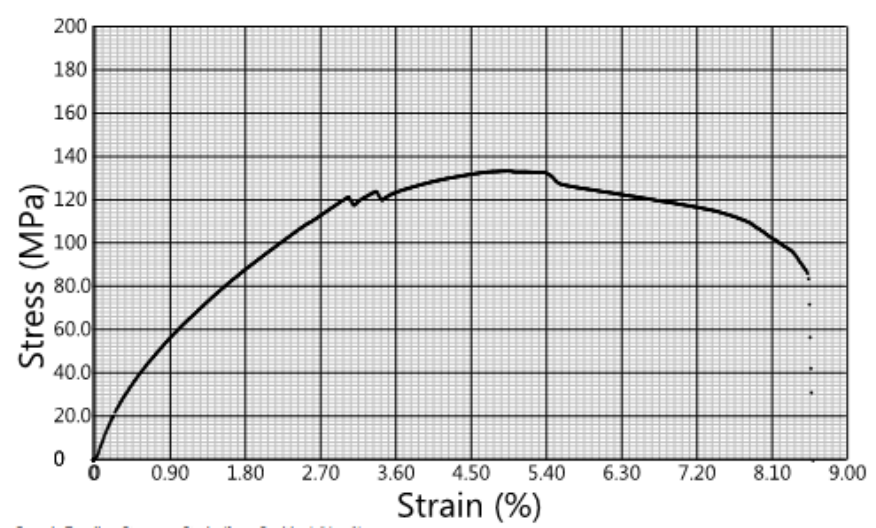

Fig.3: Stress-Strain Curve for Plate processed with square pin profile

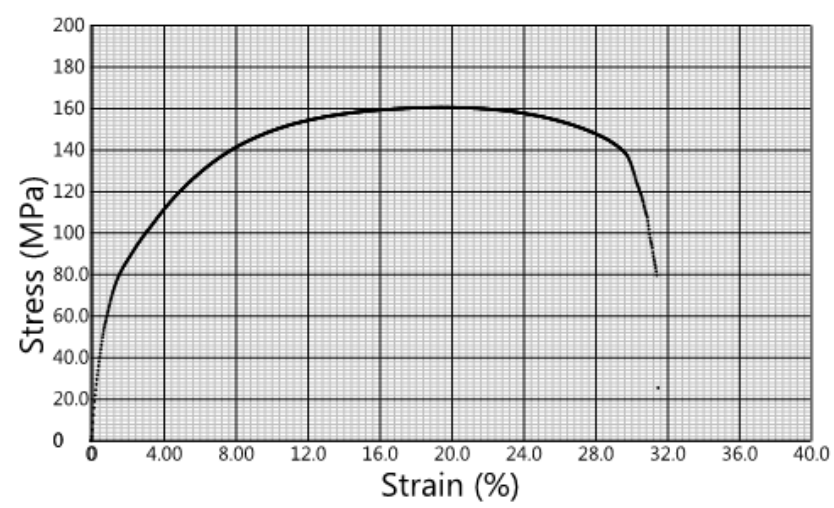

Fig.4: Stress-Strain Curve for Plate processed with metal composite and threaded Cylindrical pin profile

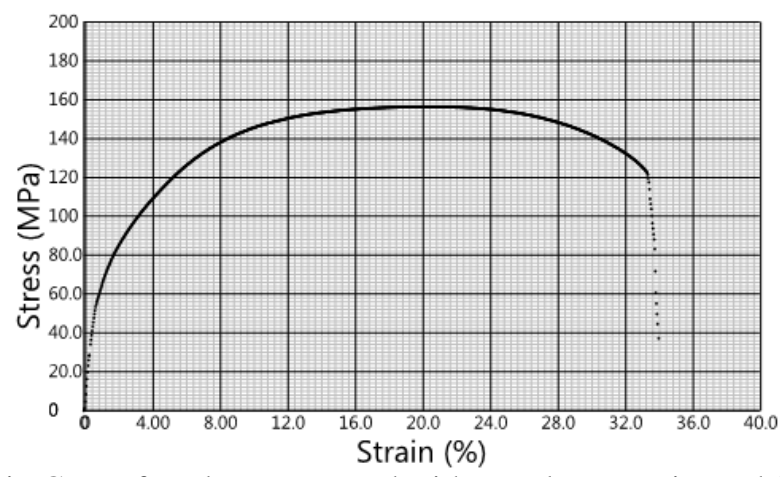

Fig 5: Stress-Strain Curve for Plate processed with metal composite and Square pin profile

In specimen processed without reinforcement, a fall in the UTS values is observed as compared to the base metal (314MPa). For specimen processed with threaded cylindrical profile tool, the UTS of $152 \mathrm{MPa}$ is higher than that of 133MPa for the square profile tool. The reason to this can be attributed to the whirling effect of the threads on the threaded cylindrical tool. But the overall decrease compared to the base metal can be attributed to the high rotational speed of 1000rpm, which on one hand did cause severe plastic deformation by breaking grains to smaller size but at the same time also led to greater heat input to the stirred zone leading to grain growth and hence deterioration of properties concerning both UTS and hardness.

The specimens processed with copper powder too showed a decline in tensile properties when compared to base metal but an increment to properties was seen when compared with the specimens processed without copper. The UTS of $161 \mathrm{MPa}$ for plate processed with $\mathrm{Cu}$ using threaded cylindrical profile was higher to that of $156 \mathrm{MPa}$ of the plate processed using square profile with $\mathrm{Cu}$. The greater strength obtained using threaded cylindrical profile is again attributed to the whirling action of revolving threads of threaded cylindrical profile which was absent in case of square profile. Also at the given combination of rotational speed (1000rpm) and traverse speed $(16 \mathrm{~mm} / \mathrm{s})$, the eccentric stirring of square profile [10] became less effective compared to the whirling action of threaded cylindrical profile. The higher strengths of the composite specimens compared to the specimens processed without reinforcement is explained with the help of Orowan Theory [5,11]. According to 
Orowan theory, when the rotational speed increases, more intermetallic phases are formed. Homogeneous distribution of particles in stirred zone pins the dislocations and enhances the strength and hardness values. With respect to given study, the intermetallic phase formed was $\mathrm{CuAl}_{2}$ which caused effective precipitation hardening. But the overall decrease in tensile properties to base metal was attributed to high rotational speed which led to high heat input and consecutive grain growth.

\subsection{Percentage Elongation}

Table 4: Percentage Elongation Values

\begin{tabular}{|l|c|}
\hline Specimen & Percentage Elongation (\%) \\
\hline Base metal without composites & 19.9 \\
\hline Threaded Cylindrical profile without composite & 30.9 \\
\hline Square Profile without composites & 33.4 \\
\hline Threaded Cylindrical Profile with composites & 9.18 \\
\hline Square Profile with Composite & 8.14 \\
\hline
\end{tabular}

With regards to percentage elongation, the specimens processed without $\mathrm{Cu}$ possessed the highest elongation values as evident from a value of $30.9 \%$ for the processing done with threaded cylindrical profile tool and $33.4 \%$ for square tool profile processing. The values obtained in case of composite processed with threaded cylindrical tool and square tool of $9.18 \%$ and $8.14 \%$ respectively are the lowest compared to the base metal with $19.9 \%$ and the non-composite specimens. This is due to the fact that the copper particles as well as the intermetallic phases formed provide pinning effect to movement of dislocations in case of composite specimens and hence lower elongation or ductility[12]. But these are absent in the specimens without composite and base metal and hence greater elongation values.

\section{Conclusion}

The UTS of the base metal (314MPa) decreases after processing without composite (133-152MPa). It was observed that the UTS of samples processed using cylindrical threaded tool profile (152MPa) is more than that of square profile (133MPa). For sample processed with copper composite using the threaded cylindrical tool pin profile, UTS of $161 \mathrm{MPa}$ whereas for the processing using square profile tool with composite, UTS of $156 \mathrm{MPa}$ was measured. Better hardness values were obtained for plates processed with composite (77HRB 84HRB) compared to those measured for non composite processed plates (64HRB-70HRB). It was also observed that the percentage elongation in the specimen without composite (30.9\%-33.4\%) were higher than those with composite.

The Al-6082-Cu MMC can have possible applications in fields requiring high surface hardness values, especially for localized treatment of machine components that suffer extensive wear during service. Also the non composite Friction Stir Processed Al- 6082 can have varied applications in fields like automotive, aerospace and other metal forming sectors that desire high plasticity as achieved through application of FSP. But the optimum values of the process parameters needs to be selected so as to avoid degradation in tensile properties.

\section{References}

[1] R.S Mishra, Z.Y Ma, I Charit, Friction stir processing: a novel technique for fabrication of surface composite, Material Science and Engineering, A 341(2003) 307-310.

[2] R.S. Mishra, M.W. Mahoney, S.X. McFadden, N.A. Mara, A.K. Mukherjee, Scripta Mater 42 (2000) 163.

[3] R.S. Mishra, M.W. Mahoney, Mater. Sci. Forum 357-359 (2001) 507.

[4] Thomas WM et al., Patent Application No. 9125978.8, December 1991.

[5] M.Zohoor, M.K. Besharti Givi, P.Salam, Effect of processing parameters on fabrication of $\mathrm{Al}-\mathrm{Mg} / \mathrm{Cu}$ composites via Firction Stir Processing, Materials and Design 39(2012) 358-365.

[6] S.Soleymani, A.Abdollah-zadeh, S.A.Alidokht, Microstructural and tribological properties of Al5083 based surface hybrid composite produced by FSP, WEAR, 278-279(2012) 41-47.

[7] Y.Morisada, H.Fujii, T.Nagaoka, K.Nogi, M.Fukusumi, Fullerene/A5083 composites fabricated by material flow during FSP, Composites Part A. 38(2007)2097-2101.

[8] Zahmatkesh B, Enayati MH, Karimzadeh F, Tribological and microstructural evaluation of friction stir processed AL2024 alloy. Mater Des 2010;31(10):4891-6

[9] Kumbhar NT, Sahoo SK, Samajdar I, Dey GK, Bhanumurthy K, Microstructural and microtextural studies of friction stir welded aluminium alloy5082. Mater Des 2011;32(3):1657-66

[10] Elangovan K, V. Balasubramanian V,Influences of tool pin profile and welding speed on the formation of friction stir processing zone in AA2219 aluminium alloy. Journal of material processing technology 200(2008) 163-175.

[11] Azizieh M.,Kokabi AH, Abachi P, Effect of rotational speed and probe profile on microstructure and hardness of AZ31/A12O3 nanocompposites fabricated by friction stir processing, Mater Des 2011;32(4):2034-41.

[12] Zhang Z, Chen DL., Consideration of Orowan strengthening effect in particulate reinforced metal matrix nanocomposites: a model for predicting their yield strength. Scripta Mater 2006;54(7):1321-6. 